\title{
Testing of Concrete Abrasion Resistance in Hydraulic Structures on the Lower Sava River
}

\author{
Andrej Kryžanowski1 ${ }^{, *}$ - Matjaž Mikoš ${ }^{1}$ - Jakob Šušteršič̌2 - Velimir Ukrainczyk ${ }^{3}$ - Igor Planinc ${ }^{1}$ \\ ${ }^{1}$ University of Ljubljana, Faculty of Civil and Geodetic Engineering, Slovenia \\ 2IRMA Institute, Slovenia \\ ${ }^{3}$ Mostprojekt, Croatia
}

The paper deals with the issues of resistance of concrete linings to long-term abrasion loading caused by waterborne particles, particularly for the proposed hydro power plants on the Sava River in Slovenia. The main purpose of the research work was to define the possibility of forecasting the process of concrete lining wear on the Sava River dam structures based on the standard procedures of abrasion resistance testing. Abrasion resistance of concrete has been researched in accordance with the standard ASTM C 1138 and Böhme (DIN 52108) methods. The research work was based on a comparison between laboratory results and measurements of abrasion resistance of concrete under natural conditions by performing test plots in the stilling basin of the Vrhovo HPP. Concrete composites with different mechanical properties have been analysed within the research programme. The analysis showed a qualitative similarity of the level of concrete abrasion between laboratory simulations and measurements in the field, as well as suitability of the ASTM C 1138 laboratory method for the assessment of abrasion resistance of concretes in the spillway of the HPP chain on the Lower Sava River.

Keywords: abrasion resistance, concrete, abrasive wear, laboratory experiments, field experiments

\section{INTRODUCTION}

An energy exploitation project that involves 6 run-ofriver cascading HPPs is underway on the lower Sava River, for which concession has already been granted and the project is under construction at present. One of the key problems inherent to the operation of energy generation facilities on the Sava River is the erosion process on the dam structures and riparian structures, as a consequence of adverse effects of water flow. Advancing erosion processes can, under extreme circumstances, produce damages to an extent causing conditions for the emergence of uncontrolled hydrodynamic phenomena with impacts reaching outside the direct area of the dam structure. The spread of uncontrolled processes means a constant, while hidden, threat for damage to occur on downstream structures and, consequently, the potential reduction of operational safety and the rise of operational costs for remedy of problems [1].

The term abrasion in hydraulic structures is used for the process of disintegration of exposed concrete surfaces, resulting from loads arising from sediment transport [1] and [2]. The rate of disintegration of the concrete surface largely depends on the transport capacity of water and the ways of transport of solid matter [3] and [4]. When designing concretes in hydraulic structures it should be emphasised that there is no general criterion for defining abrasion resistance. Usually, abrasion resistance of concretes is assessed based on a set of parameters that define the single mechanical properties of concretes, such as: compressive strength, tensile strength, aggregate strength, use of special cements, modulus of elasticity, water/cement $(\mathrm{w} / \mathrm{c})$ ratio, surface polishing, concrete cure, cement additives (fly ash, fibres), connected with investigating methods that more or less realistically simulate abrasive processes [5] to [10]. The problem of studying abrasion resistance of concretes arises from the inability to create proper hydraulic laboratory conditions for the fully developed abrasive action. In general, two groups of methods are used in the research of abrasion resistance of concretes.

The first group of methods uses procedures involving uniform abrasion of the test surface with the abrasive body, which is in relative movement. These methods are most frequently used for determination of abrasion resistance of concrete surfaces (industrial floors, roads, walk able surfaces etc.). Among these methods, the standardized method utilising the Böhme (DIN 52108) principle is most comprehensively applied, where the surface of the concrete specimen is exposed to a rotating grinding disk [11]. To accelerate the wear process, an abrading agent (corundum, silicon carbide etc.) is applied to the disk or the test is performed in the presence of a water medium. A similar principle for establishing abrasion resistance of horizontal concrete surfaces is prescribed by the ASTM C 779/C-779M standard, providing three test procedures simulating the action of the abrasive medium against the surface of the concrete specimen using: (a) revolving disks; (b) dressing wheels; (c) ball bearings. The advantage of abrasive methods is that they mostly follow standard procedures, which enables good comparison between experimental results [12]. The disadvantage, however, lies in the 
fact that they do not simulate the actual conditions of abrasion in hydraulic structures, thus representing a limitation to their application [1] and [13]. In order to accelerate the wear process a method with high water pressure jet was developed [2]. The above mentioned method simulates cavitation or impact erosion in similar manner as in [14] and [15].

The second group of methods that enable the modelling of tribology mechanisms of the water current with bed load come closest to the conditions present in the natural environment [1] and [13]. In order to test the abrasion resistance of concretes several methods were developed illustrating the action of the water current carrying bed load: Šetina [16] has studied abrasion resistance of concrete with water current and an abrasive device (siliceous sand) in a circular flume Liu [17] has reported on the development of a test method, where the concrete test specimen is in a cylindrical container exposed to the abrasive action of steel balls. The method was standardized by the procedure prescribed by ASTM C 1138 [18]. Bania [19] has reported on the development and studies of a test method, which is composed of a fixed steel drum, which is partly filled with a mixture of water and aggregate, and a rotating drive shaft with fixed tested concrete samples.

Common to the methods investigating abrasion resistance is that they provide only qualitative comparisons between the tested specimens, based on a proportional loss of mass or input of the abrasive medium during the investigation. The validation of results and applicability of the methods for forecasting the behaviour of concretes in natural conditions can only be achieved by performing the test under the conditions similar to those in the actual operation environment of the designed structure, including the monitoring of all relevant hydraulic and hydrological parameters [5] and [20]. Testing abrasion resistance of specimens under natural circumstances is highly difficult due to the specific conditions of execution mentioned and the related costs. In the literature, there has been a single case documented, which is that of the Runcahez site in Switzerland, where the abrasion resistance of concretes was compared following the method proposed by Bania, using the measurements in the test fields of the main outlet of the dam. In the conclusion of the study, a correlation of the results of measurements in the nature with those in the laboratory was established [13]. When studying the adequacy of abrasion-resistant concretes in building the HPP chain on the Sava River a similar investigation was made, using test fields in the Vrhovo HPP spillway, while the correspondence of the results was checked against the
ASTM C 1138 and Böhme test methods. One of the key goals of this study was to establish the possibility of forecasting the development of concrete wear on the Sava River dam structures based on the results of testing abrasion resistance using the standard procedures [1].

\section{PROBLEM DOMAIN}

The Sava river has a typical torrential character with considerable hydrological extremes that are reflected in the fluctuation of discharge (from 40 to $3,000 \mathrm{~m}^{3} / \mathrm{s}$ ) with highly marked bed-load discharge [21]: the usual annual bed-load discharge is $66,000 \mathrm{~m}^{3}$ per year (mostly limestone), with extremes exceeding 260,000 $\mathrm{m}^{3}$ per year and suspended load discharge reaching up to $100,000 \mathrm{~m}^{3}$ per year. Based on sieve analyses and 20-year observations of sediment transport, the arithmetic mean grain size diameter is $d_{m}=30.9 \mathrm{~mm}$ and at $90 \%$ passing value $d_{90}=72.5 \mathrm{~mm}$. Based on the calculated transport capacity of the Sava River after the construction of the Vrhovo HPP, as the first hydro power plant in the chain, it became evident that the majority of the sediment would be retained in the reservoir. The washing of the sediment from the reservoir would become possible only when the Sava river flow would exceed $630 \mathrm{~m}^{3} / \mathrm{s}$. The transport capacity of the river rises proportionally to its flow and reaches natural conditions, prior to the damming, at $2,500 \mathrm{~m}^{3} / \mathrm{s}$, representing a 20 -year return period. Based on the monitoring of abrasive action in the existing dam structures it can be established that sediment loaded discharge represents a latent danger when trying to ensure operation security of objects and functionality of evacuation structures [22].

A typical dam structure on the lower Sava River is composed of a powerhouse and 5 spillways, transversal to the river flow. Each spillway is equipped with a segmental gate with a flap. To the level of the installed discharge $Q=500 \mathrm{~m}^{3} / \mathrm{s}$ HPP operates in the run-of-river flow regime, and the evacuation of flood water is through flap gates (up to $365 \mathrm{~m} / \mathrm{s}$ on Vrhovo HPP) or by outflow under the segmental gate. Under normal operating conditions, based on the calculated transport capacity of the Sava river on the evacuation structures of the dams, the flow of sediment in the form of suspension or bed load with a grain diameter of $d=1 \mathrm{~mm}$ or less is expected. During extreme flow of the Sava River when the discharge exceeds 1,200 $\mathrm{m}^{3 / \mathrm{s}}$, the natural flow regime is established through the underspill below the gates and de-levelling of the water level. The natural flow regime through the dam section is achieved by full opening of the 
gates, which is achieved at $2,500 \mathrm{~m}^{3} / \mathrm{s}$. Under such conditions the transport of coarse grains is expected. Because of such operation regime, the exposed parts of spillways, where abrasive erosion is to be expected, are covered with abrasion-resistant concrete lining [5] and [22]. In designing abrasion resistant concretes it was necessary to solve a number of questions related to the proper concrete composition to be able to determine the appropriate research methods, the application in the field and, last but not least, to check the material resistance during the exploitation. As part of intervention/remedial measures on the spillways of the Vrhovo HPP the possibility of performing a research project was provided, studying the adequacy of technologies producing abrasion resistant concrete linings and the methods for testing abrasion resistance of materials. The research project enabled the introduction of test plots in natural conditions trying to realize, among others, the following goals [1]:

(i) To enable quantification of results of the laboratory method investigating abrasion resistance compared to measurements in the natural environment.

(ii) To enable forecasting of behaviour of material during exploitation.

\section{ABRASION EROSION}

The general tribological structure of wear of concrete surfaces in hydraulic structures can be described as follows: (i) the basic body being motionless, is the concrete surface of the construction, and (ii) the body acting upon the concrete surface, being in motion, is represented by the water current running past the concrete surface. The term abrasion erosion in hydraulic structures is used to describe the wear of the solid surface being the result of action of the water current past the surface with associated hydrodynamic phenomena and solid particles (sediment) transported with the water current. The emergence of abrasive erosion on concrete surfaces of hydraulic structures can be caused by action of deterioration processes (abrasion) due to:

- friction forces during sliding and rolling of sediment grains transported by the water current in contact with the concrete surfaces,

- impact forces of sediment grains transported by the water current upon impact with the concrete surface and pressure pulsations in the surrounding water body.

Accordingly, the abrasion erosion of concrete can be divided into several phases. In the initial phase, the process of abrasion is caused by sediment transport.
The damage to concrete structures thus results from polishing/milling due to rolling or sliding of sediments (solid particles) against the surface. By increased transport capacity, the small particles start to move in suspension, and large solid particles move by way of bouncing. In this phase, the abrasion process depends on bed load transport or suspended matter. In addition to the grinding action against concrete surfaces, damage due to impacts of solid particles against the surface may be observed. By increased transport capacity the size and quantity of bouncing particles increase significantly, and, simultaneously, pressure pulsations in the water increase. This contributes to the intensity of the abrasion process. The emerging damages on concrete surfaces are related to the increase of the size of solid particles and the intensity of impacts against the bottom, where at first initial damages occur, which represent, with progressing processes, the core of progressive spreading of the damage in the direction of the water current [4] and [20].

Damages to concrete surfaces are the result of hydrodynamic processes of the water flow and abrasive action caused by waterborne particles striking against the base. The impacts of the water flow in the process of failure can be expressed by shear stresses acting on the surface as a consequence of water action, normal stresses, and pressure within the body of the hydro structure. Waterborne particles act against the surface due to their characteristic movement: rotation, translational motions, saltation, or a combination of these. Abrasive action of waterborne particles causes the development of fine cracks on the surface and within the concrete structure. The cracks develop due to the exceeded limited tensile stresses in concrete. Tensile and compressive forces accelerate the development of cracks, weaken the structure (material fatigue strength) and destroy the internal bonds in the structure, while the water flow starts to wash away the particles of cement binder and aggregate. The degradation process continues in the interior of the structure revealing visible damages. The deterioration process is even faster in turbulent waters due to the dynamic phenomena (pressure pulsation, vibrations in the structure and strokes of particulate matter against the foundation). The failure of concrete structure occurs both in the cement and in the aggregate, mostly along the interface between the cement binder and the aggregate, where repeated dynamic processes widen the initial cracks and weaken the contact. The damages caused by the abrasive water action are characterized by roughness, irregularly corroded surface with hollows and swellings in the basic structure. Abrasion 
erosion on hydro structures typically occur on exposed parts of evacuation structures, such as: spillways, outlet channels, by-pass channels, stilling basins, drainage outfalls and culverts [20].

A number of experimental methods which more or less realistically illustrate the abrasion process are used in practice. The purpose of all test methods is to obtain the relevant parameters within the real time to assess the quality of the material. Consideration is to be given to the fact that due to the complex problem solving, only a comparative evaluation of the results is possible. Therefore, it is reasonable to use such an experimental method that will give the real data in a short period of time and enable comparison of the results with the results obtained from other sources at the same time. When choosing an adequate method the following starting points were considered:

- The method of testing abrasion resistance must illustrate the expected conditions of transport of bed load and suspension along the evacuation structures on the hydro structures of the Sava river as faithfully as possible.

- The testing procedure of abrasion resistance must be standardised, thus providing the repeatability of the test and the possibility of comparison of the results of measurements with those from the literature.

- The performance of the test must be economical - the purchase of testing equipment and the duration of the test are of significance, which must be comparable to the standard methods for testing the quality of hardened concrete.

- To ensure the comparability of results of measurements those methods testing abrasion resistance that have already been used for the demonstration of quality of building the Lower Sava river HPPs need to be included.

These starting points provided the grounds for choosing two standard methods for testing abrasion resistance in our research.

\subsection{The Grinding Method after Böhme}

The test of resistance of concrete specimens to grinding was performed following the procedure prescribed by standard DIN 52108. The test was performed on standard specimens (cubes with 7.1$\mathrm{cm}$ sides) at 90-day age, using three samples per composition. The specimen was clamped and fixed to the mounting holding it against a rotating grinding disk that provided a uniform grinding of its surface. The specimen was weighed before the test and then each time after a set of 4 cycles (one cycle consisted of
22 revolutions of the grinding disk) at $0.1 \mathrm{~g}$ accuracy. An abrading agent (corundum, quartz sand etc.) can be applied, in dry or wet state, thus accelerating the rate of deterioration. The prevailing deterioration process is abrasion through grinding; typically occurring in roads, walk able surfaces etc. The result of the test is the wear of concrete after 16 cycles, which is determined by the loss of volume of the specimen in $\mathrm{cm}_{3}$ in an area of $50 \mathrm{~cm}^{2}$.

Indeed, the method does not simulate the real conditions of the abrasion process on hydraulic structures, but its applicability lies in the fact that this is a standardised procedure that is generally used in the research of abrasion resistance. Until recently, the demonstration of abrasion resistance to grinding after Böhme in Slovenia had been the only standardised method of testing abrasion resistance and therefore the only possible qualitative comparison with the results of measurements of abrasion resistance performed in the past. Based on the comparative analysis the quality class of the tested samples can be predicted and therewith the starting points for qualitative comparisons of results of abrasion resistance of concretes with other chosen test methods.

\subsection{Abrasive Erosion Method after ASTM C1138}

The abrasion resistance test was performed in accordance with standard ASTM C 1138 method at 90- and 900-day ages, on cylinders of Ø30/10 $\mathrm{cm}$, taking one sample per composition. The test method is designed to duplicate the abrasive action of waterborne particles in the stilling basins. Circulating water moves the steel grinding balls on the surface of a concrete sample, producing the desired abrasion effects. The water velocity and agitation effect are not sufficient to lift the steel balls off the surface of the concrete sample to cause any significant impact action against the surface. The test method can only be used to determine the relative resistance of the material to the abrasion action of waterborne particles. The standard procedure of the investigation provides for the measurement of the wear of specimen surface at 12-hour intervals; the total investigation time is 72 hours. The result of the test is the average depth of wear expressed by the average volume of wear on the surface of the specimen in the duration of the test.

Of all the methods used, this method provides the most adequate illustration of the real conditions during the transport of bed load along the concrete surfaces. The applicability of the method is that it is standardised, making it possible to provide a qualitative comparison of the results of measurements 
of previous studies and the data from the literature. In Slovenia, the method was first used for experimental purposes, simultaneously to the start of building of the Vrhovo HPP. This is why there are relatively large data sets on the measurements performed, enabling relatively good qualitative comparisons of the adequacy of concrete compositions in relation to achieving abrasion resistance. The disadvantage of the method is the prolonged duration of the test, and in addition to the limited equipment available, this is restricting the potential large-scale investigations. Therefore, the preparation of specimens is adapted to the frame available for the performance of the test, thereby optimising the scope and duration of testing. The advantage of the method, however, is that the procedure is selective enough to provide representative results for qualitative assessment of abrasion resistance.

\section{MEASUREMENTS IN NATURAL CONDITIONS}

In 2001, a total of 9 test plots, dimensions of 2.5/2.5 m, thickness of $0.1 \mathrm{~m}$ at a distance of $1.0 \mathrm{~m}$ (Fig. 1), were built at the bottom of the Vrhovo HPP spilling basin. Out of these, 6 fields were equipped with concretes of laboratory compositions, and the rest were fitted with commercial high-strength concretes. Concrete mixtures were prepared by using Portland cement with $15 \%$ slag, gravel aggregate (mostly limestone), grading 0 to 8 (16) $\mathrm{mm}$, and super plasticizer. Six samples of different concrete composition were intended for test purposes (Table 1): The $\mathrm{C} 1$ composition is adopted as control composition, which is basically the same as the composition of abrasion resistant concrete built in the spillways of the Vrhovo
HPP. In C2 composition and all further modifications the nominal maximum gravel of $8 \mathrm{~mm}$ was adopted. The C2 composite with smaller modifications was used with concretes on the spillway of the Boštanj HPP. With the PMC1 composition, representing the initial composition for all further modifications, the mineral additive and super plasticizer were replaced by polymeric binder: (i) in the $\mathrm{PMC} 2$ composition the proportion of the finest fraction (0 to $4 \mathrm{~mm}$ ) was replaced by rubber aggregate and the proportion of polypropylene fibres was doubled; (ii) in the PMC3 composition the polypropylene monofilament fibres were added; (iii) in the PMC4 composition the proportion of the polymeric binder was halved. The value of the $\mathrm{w} / \mathrm{c}$ ratio in the composites did not vary considerably.

The properties of the hardened concrete were proven with the standard investigation methods. The average values of investigation results of the hardened concrete are given in Table 2: (i) Compressive strength and density were performed at the ages of 3, 7, 28 and 90 days, respectively, on cubicles of dimensions of 15 $\mathrm{cm}$, by taking three samples of each composition; (ii) The static modulus of elasticity of the concrete was defined at the 90-day age on prisms of $10 / 10 / 40 \mathrm{~cm}$, taking one sample per each composition; (iii) Abrasive resistance test was performed at 90- and 900-day ages, on cylinders of $\varnothing 30 / 10 \mathrm{~cm}$, taking one sample per composition.

The concrete composites were transported to the construction site in the form of prefabricated dry mixtures. The preparation of concretes of the test plot was performed following the same procedure as for laboratory concretes. The concretes were built in manually, using a vibration pin, and afterwards

Table 1. Overview of concrete compositions (for $1 \mathrm{~m}^{3}$ of concrete)

\begin{tabular}{|c|c|c|c|c|c|c|c|c|}
\hline & & & $\mathrm{C1}$ & $\mathrm{C} 2$ & PMC1 & PMC2 & PMC3 & PMC4 \\
\hline \multicolumn{2}{|c|}{ CEMENT } & {$\left[\mathrm{kg} / \mathrm{m}^{3}\right]$} & 440 & 450 & 450 & 450 & 450 & 450 \\
\hline \multicolumn{2}{|c|}{$\mathrm{W} / \mathrm{C}$} & & 0.391 & 0.414 & 0.416 & 0.416 & 0.416 & 0.412 \\
\hline \multicolumn{2}{|c|}{ SUPERPLASTICIZER } & $\%$ mass of cem. & 0.9 & 0.9 & & & & \\
\hline \multicolumn{2}{|c|}{$\begin{array}{l}\text { MINERAL SUPPLEMENT: } \mathrm{SiO}_{2}>90 \% ; \mathrm{Al}_{2} \mathrm{O}_{3} 0.5 \sim 1 \% ; \\
\text { CaO 0.5 1\%; } \mathrm{Na}_{2} \mathrm{O} 0.5 \sim 1 \%\end{array}$} & $\%$ mass of cem. & 5 & 5 & & & & \\
\hline \multicolumn{2}{|c|}{ POLYMER - DRY PORTION } & $\%$ mass of cem. & & & 10 & 10 & 10 & 5 \\
\hline \multicolumn{2}{|c|}{$\begin{array}{c}\text { STEEL FIBERS: } \\
\mathrm{L}=16 \mathrm{~mm}, \emptyset 0.5 \mathrm{~mm}\end{array}$} & $\%$ of vol. & 0.5 & 0.5 & 0.5 & & & \\
\hline \multicolumn{2}{|c|}{ PP FIBERS: $\mathrm{L}=10 \mathrm{~mm}, \varnothing 30 \sim 40 \mu \mathrm{m}$} & $\%$ of vol. & 0.05 & 0.05 & 0.05 & 0.10 & 0.05 & 0.05 \\
\hline \multicolumn{2}{|c|}{ PP MONOFILAMENT FIBERS: L=30 mm, $\emptyset 0.5 \mathrm{~mm}$} & $\%$ of vol. & & & & & 0.60 & \\
\hline \multirow{3}{*}{ GRAVEL AGGREGATE } & 0 to $4 \mathrm{~mm}$ & \multirow{3}{*}{$\%$ of vol. } & 48 & 69 & 70 & 56.9 & 70 & 69.4 \\
\hline & 4 to $8 \mathrm{~mm}$ & & 15 & 31 & 30 & 33.6 & 30 & 30.6 \\
\hline & 8 to $16 \mathrm{~mm}$ & & 37 & & & & & \\
\hline RUBBER AGGREGATE & 0 to $4 \mathrm{~mm}$ & $\%$ of vol. & & & & 9.5 & & \\
\hline
\end{tabular}


they were manually finished. In the next 14 days an intensive wet curing with additional covering of the test plots with PVC foil was carried out. Before the overtopping of the stilling basin a levelling of all irregularities in contact points with concrete base was conducted together with a surveying campaign measuring the surface area of test plots with an accuracy $\pm 10^{-4} \mathrm{~m}$, and elevation was determined based on the existing bench-mark network on the dam. In order to exclude the influence of boundaries (dimension of $0.5 \mathrm{~m}$ ), the campaign was performed only in the central part of test plots (dimensions of $1.5 / 1.5 \mathrm{~m}$ ), in a raster of $30 \times 30 \mathrm{~cm}$, and in a total of 36 measuring stations. After the surveying campaign, the test plots in the stilling basin were filled with water and operation of the spillway was blocked until the required 90-day age of the test concrete.

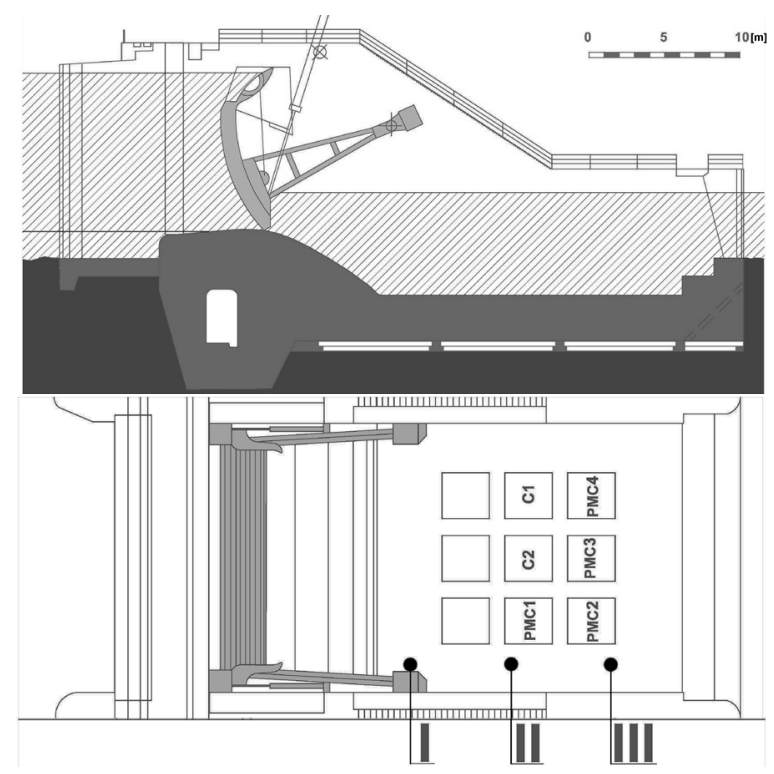

Fig. 1. Location of test plots and the control profiles of base concrete in the stilling basin of the Vrhovo HPP spillway

Table 2. Results of investigations of hardened concrete

\begin{tabular}{|c|c|c|c|c|c|}
\hline & \multirow{2}{*}{\multicolumn{2}{|c|}{$\begin{array}{c}\begin{array}{c}\text { Compressive } \\
\text { strength } \\
\text { SIST EN 12390-3 }\end{array} \\
{[\mathrm{MPa}]}\end{array}$}} & \multirow{3}{*}{$\begin{array}{c}\begin{array}{c}\text { Modulus of } \\
\text { elasticity } \\
\text { DIN 1048-5 }\end{array} \\
{[\mathrm{GPa}]} \\
90 \text { days } \\
\end{array}$} & \multirow{2}{*}{\multicolumn{2}{|c|}{$\begin{array}{c}\text { Wear } \\
\text { ASTM C } 1138 \\
{[\mathrm{~mm}]}\end{array}$}} \\
\hline & & & & & \\
\hline & 28 days & 90 days & & 90 days & 900 days \\
\hline $\mathrm{C} 1$ & 62.33 & 67.17 & 31.17 & 1.79 & 0.98 \\
\hline $\mathrm{C} 2$ & 73.09 & 79.17 & 35.43 & 1.64 & 1.16 \\
\hline PMC1 & 51.12 & 54.05 & 26.43 & 2.09 & 2.42 \\
\hline PMC2 & 22.45 & 23.81 & 16.37 & 0.61 & 0.60 \\
\hline PMC3 & 46.90 & 49.06 & 22.36 & 1.79 & 1.92 \\
\hline PMC4 & 54.79 & 58.4 & 25.75 & 2.81 & 1.84 \\
\hline
\end{tabular}

The program of monitoring operational characteristics in the test plot plots commenced with setting-up of the spillway in function in February 2002, and ended in August 2004. The records on operational manoeuvres, discharges over spillway and on the Sava river flow were held based on hourly records from the operational journal of the hydroelectric power plant. The transport of sediments in the dam cross-section was not directly monitored, but an assessment was performed based on the known discharges of the Sava river during the operational manoeuvres and sediment discharge curve in the dam cross-section, which was obtained from years of measuring turbidity and sediment transport in the Vrhovo storage reservoir [21]. During the entire investigation period we registered a total of 804 operation hours with the operation of the spillway, while the condition for sediment transport was met in a total of 297 operation hours. During the time, the transport of over 1,937 t of sediments was recorded in the spillway area at a total discharge of $204.73 \mathrm{hm}^{3}$ of water, which was on average $\sim 0.01 \%$ of mass flow of water and solid particles over the spillway.

The geodetic surveying of wear of test plot surfaces was performed in measuring stations that were height-referenced to the bench marks on the dam, following the same procedure and using the same equipment as in the campaign performed after the introduction of test plots. Special attention was required for the implementation and interpretation of the measurements. The average of the wear depth of the test plots varied from $2 \times 10^{-4} \mathrm{~m}$ in the test plot $\mathrm{C} 2$ to $8 \times 10^{-4} \mathrm{~m}$ in the test plot PMC4. The measuring equipment enabled the measuring precision of $\pm 10^{-4} \mathrm{~m}$. For the interpretation of the measurements we therefore excluded all the stations where no changes had been registered or where extra values compared to the starting point had been registered, which gave rise to the doubt about the credibility of the measurement.

Based on the conclusions of the modelling studies it was assumed that, due to the changing velocity of the water current, the wear of concrete surfaces in the stilling basin cannot be uniform [22]. The estimate of the scale of the wear of the existing base concrete in the stilling basin was performed based on the measurements of the size of wear of representative grains of the aggregate $d=64 \mathrm{~mm}$ of the existing base concrete, that is, in the belt between the pillar and the test plots in a total of 21 control profiles. In each control profile we measured the diameter of representative grains on the surface of $500 \mathrm{~cm}^{2}$ with raster grid of $2 \mathrm{~cm}$. It was found that the characteristic diameter of the largest grain in the 
profile of the plots $(\mathrm{K} 1, \mathrm{~K} 2, \mathrm{~K} 3)$ was $5 \mathrm{~mm}$, in the profile of plots $(\mathrm{C} 1, \mathrm{C} 2, \mathrm{PMC} 1) 9 \mathrm{~mm}$ and the profile of plots (PMC2, PMC3, PMC4) $11 \mathrm{~mm}$ (Figs. 1 and 2 ). The measurements have shown that the wear of the base concrete increases linearly downstream, that is, from the assumed starting point right under the chute. The wear in the central line of the plots $(\mathrm{C} 1$, $\mathrm{C} 2, \mathrm{PMC} 1$ ) increases by a factor of 3.3 as to the initial value, and in the central line of the plots (PMC2, PMC3, PMC4) by a factor of 5.7, respectively. In processing of results, the values obtained for test plots were multiplied with the corrective factors, depending on the location, so that the measurement results were converted to a common denominator.
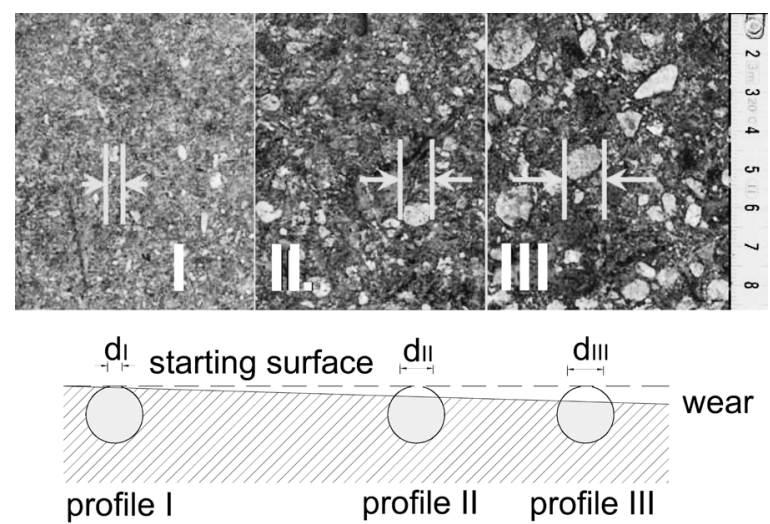

Fig. 2. The level of wear of the existing base concrete in the control profiles, in a distance from the chute of: (I) $1 \mathrm{~m}$; (II) $7 \mathrm{~m}$; (III) $13 \mathrm{~m}$

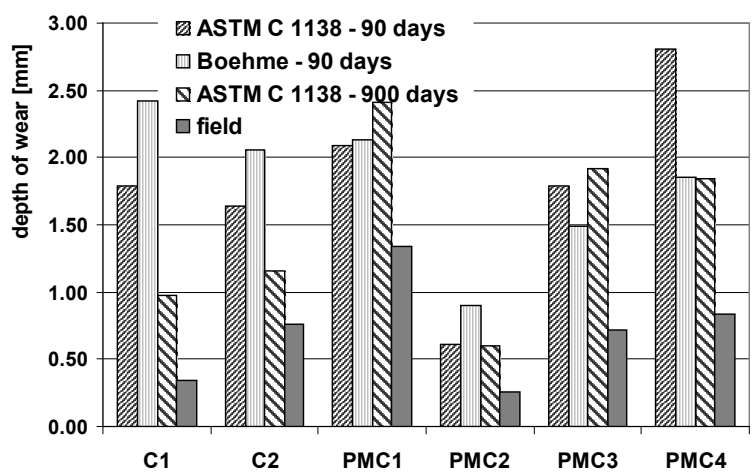

Fig. 3. Comparison of wear between concrete compositions after ASTM C 1138 and Böhme and measurements in the test plots

Fig. 3 shows the measurement results of abrasion resistance following the procedures after the Böhme method at the specimen ages of 90 days and the ASTM C 1138 method at the specimen ages of 90 and 900 days, respectively, and the corrected results of abrasion resistance in the test plots, after approximately 2.5 years of operation. The following findings were made:

- According to the depth of wear obtained after both standard test procedures and through comparison of the results of measuring abrasion resistance from the literature, it can be established that all the investigated concrete compositions can be classified as concretes highly resistant to the abrasive action of the water current, which also provides a validation of the proper composition for abrasion resistant concretes on the Lower Sava River dams.

- It can be drawn from the comparison that there is a similarity between the wear of the test concretes subject to laboratory conditions and those in the natural environment.

- According to the control C1 composition, a considerable improvement of resistance to wear in composition with the added rubber aggregate PMC2 was achieved.

- It became evident that abrasion resistance changes with the age of specimens: at the 900day age, the achieved resistance in the PMC2 composition was still higher than the control composition; however, the improvement of resistance with age with the $\mathrm{C} 1$ composition is considerably higher than in PMC2 composition. The abrasion resistance increased with age also in the $\mathrm{C} 2$ and PMC4 compositions, but it decreased in compositions with polymeric binders (PMC1 and $\mathrm{PMC} 3$ ); in all compositions it remained smaller than the control composition.

In the research work an influence of various parameters on resistance of concrete was studied in detail (e.g. mechanical properties of concrete such as: compressive strength, tensile-flexural strength, split, etc.). It was shown that the usefulness of abrasion resistance methods was independent of parameters considered above. As a result, these conclusions are not explicitly included in this paper however they are presented in reference [1].

\section{ANALYSIS OF RESULTS}

The comparison of results between the laboratory measurements and measurements in test plots showed the similarity between the wear samples of both investigations. The findings were checked with the regression analysis where the measurements on the test fields were analysed with laboratory measurements. 


\subsection{The Böhme Method}

When analysing the results obtained after the Böhme method the correlation with the measurements in the field $\left(R^{2}=0.15\right)$ could not be confirmed; the comparison of results of composition of concretes with polymeric binder gave a better correspondence of results $\left(R^{2}=0.93\right)$, which is probably due to the similar mechanical properties of the concretes. Also, the coherence of the results obtained by the Böhme and ASTM procedures could not be confirmed $\left(R^{2}=0.37\right)$. Similar findings are reported by other researchers [2] and [7].

When testing abrasion resistance of concretes on the spillways on the Lower Sava HPPs, using the Böhme procedure, the applicability of the testing was revealed, however, the comparability of measurements in the laboratory and in the field was valid only for those compositions of concrete that had similar mechanical properties. Regarding further studies of abrasive resistance of concretes on the structures on the Sava River, the testing after Böhme should remain included, while it would be recommended to include the results of wear after single duration cycles in order to recognize the potential influence of testing duration to the correlation of the results with the measurements in natural conditions.

\subsection{ASTM Results}

The comparisons with the results of laboratory measurements in the entire duration of investigation of 72 hours and measurements in test plots have shown that based on the coefficient of correlation, at the 90-day age $\left(R^{2}=0.37\right)$, it is not possible to confirm the dependence between the measurements; at the 900-day age of specimens $\left(R^{2}=0.83\right)$ a fairly good correlation between the measurements is confirmed. By taking into consideration the results of laboratory measurements of wear in the single cycles of the duration of the investigation it was found for the 90-day specimens that the best correlation was that between the measurements after 24 hours into the investigation, when a rather good correlation was identified $\left(R^{2}=0.79\right)$. For the 900 -day specimens the best correlation between the measurements was found after 36 hours of investigation duration, when an excellent correlation was obtained $\left(R^{2}=0.98\right)$. The comparison of the results of the investigations for the durations of investigations analysed is seen in Fig. 4, where only the deviation in the PMC1 composition is evident, while in other compositions the correlation of results is satisfactory.

\subsection{Prediction of the Concrete Wear Process}

In the final part we analysed the possibility of predicting the processes of concrete wear in the test fields on the basis of operational data and the estimated bed load through the spillway, by taking into consideration the results of testing abrasion resistance using the ASTM C 1138 method. To make an estimate of the prediction, the following data on the spillway operation were available: operation duration with bed load discharge and the volume of sediment being transported through the spillway during the time of investigation. Based on the time of operation and the sediment volume the mass discharge was determined, i.e. the sediment volume passing through the spillway in a unit of time.

In the calculation it was assumed that sediment travels with the speed of the water current in the stilling basin, which was determined based on the model research, on average being around $20 \mathrm{~m} / \mathrm{s}$. It was also considered that the concentration of sediment in the water current is the same along the width of the flow and that the uniformly distributed sediments are in translatory motion with the water current along the concrete surface in the stilling basin. The specific energy is the released kinetic energy of the moving mass of sediment on the concrete surface in the stilling basin of the spillway. A similar estimate of the kinetic energy released was made for the test cylindrical container following the ASTM C 1138 method, where the balls move on the bottom with an average speed of $1.8 \mathrm{~m} / \mathrm{s}$. The relationship of the specific energy of the moving sediment in the test fields and the moving balls in the test container is approximately 1:10 (Table $3)$.

Based on the relationship between the released specific energy we can make a rough estimate that 297 operational hours in the test fields in the time of the research correspond to approximately 30 hours of duration of investigation of abrasion resistance according to the ASTM C 1138 test method. The estimate corresponds well with the analysis of the results of laboratory tests and measurements in test fields, where the best correspondence with the measurements in natural conditions was obtained after 24 hours (at the 90-day age of specimens) and after 36-hour duration of the laboratory experiment (at the 900-day age of specimens), respectively. Considering the fact that the age of concretes in the test fields during the duration of experiment was between 90 and 900 days, the wear after 30 hours of the test under laboratory conditions is the exact value to be expected after performing the testing after ASTM C1138 at a 
comparable age of specimens, considering the natural conditions. Accordingly, the expected values of wear of specimens of comparable ages with those in the natural conditions are within the values corresponding to the wear after 30 hours of testing with the upper boundary at the 90-day age of specimens and the lower boundary at the 900-day age of specimens (Fig. 4).

Table 3. Estimation of mass discharge and released kinetic energy

\begin{tabular}{lcc}
\hline & Mass flow of particles $[\mathrm{kg} / \mathrm{s}]$ & Specific energy $\left[\mathrm{J} / \mathrm{m}^{2}\right]$ \\
\hline Test fields & 3.13 & 2.08 \\
\hline ASTM C 1138 & 1.03 & 23.5 \\
\hline
\end{tabular}

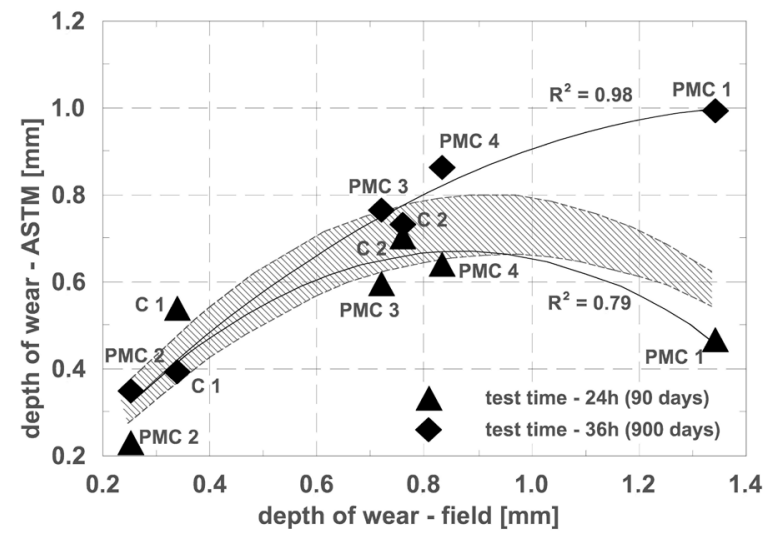

Fig. 4. Comparison of wear between the ASTM C 1138 results, at 90-day age (after 24 and 72-h duration of investigation) with measurements in the test plots

In order to confirm the estimate provided above it would be necessary to repeat the measurements of wear in the test fields, analyse the operational characteristics and monitor the hydrologic parameters during the execution as part of regular operational monitoring. For a more precise quantification of sediments it would be necessary to set up permanent monitoring of concentration of suspension in the reservoir and downstream of the dam and perform continuous measurements of movement of gravel zones in the reservoir. The continuous monitoring of sediment would help to narrowly define the volume of sediment transport and the way of transport through the dam - in the form of bed load or in suspension. The setting up of a permanent monitoring of dynamics of sediment transport in the reservoir area is important from the aspect of flood safety (clogging of the reservoir) as well as providing the possibility of a more accurate estimation of abrasive action in the spillways of energy generation facilities on the Sava River.
If the repeated measurements would once again show the correlation between the mass discharge of sediment in the time of operation of spillways on the hydropower plant and the mass discharge in the test container used in the ASTM C 1138 test method under laboratory conditions, this would additionally confirm the adequacy of selecting the method of testing abrasion resistance using the ASTM C 1138 method for prediction of abrasion processes of concrete surfaces on evacuation structures of the Lower Sava River hydropower plants.

\section{CONCLUSIONS}

In the paper we presented the suitability of the laboratory methods for the assessment of abrasion resistance of concretes in hydraulic structures on the Lower Sava River by performing a comparison between laboratory measurements and measurements in the natural environment. The following has been established:

- Good correlation between the results of investigation of abrasive resistance according to the ASTM C 1138 procedure and measurements in the natural environment for concretes of 900day age.

- The testing of abrasion resistance after the Böhme procedure revealed the applicability of the test, taking into account certain limitations, since the comparability of the results of abrasive resistance is possible only with those concretes that have similar mechanical properties. Owing to the ease-of-use and short duration of the test, it is recommended that the test remains to be part of further research of abrasion resistance of concretes on the Lower Sava River structures, while, however, it might be worth considering, including the results of single cycles of testing duration, as is the case with the ASTM method.

- In the analysis of abrasion resistance according to the ASTM C 1138 procedure and interpretation of measurement results, important parameters are the duration of investigation and the age of the specimens during the investigation.

- Suitability of the ASTM C 1138 laboratory method for the assessment of abrasion resistance of concretes in spillway of the HPP chain on the Lower Sava River.

- The possibility of forecasting the dynamics of concrete wear on dam structures on the Lower Sava River has been indicated based on the ASTM C 1138 test. The thesis should be supported by an extensive programme of monitoring the dynamics 
of wear of concrete surfaces in dam structures, operational characteristics and hydrologic parameters.

\section{REFERENCES}

[1] Kryžanowski, A. (2009). Abrasion Resistance of Concrete on Hydraulic. Structures Ph.D. thesis. University of Ljubljana, Ljubljana.

[2] Kryžanowski, A. (1991). Analyses of concrete resistance to deterioration due to water action. M.Sc. thesis. University of Ljubljana, Ljubljana. (in Slovenian)

[3] Mikoš, M. (1993). Fluvial abrasion of gravel sediments., Acta Hydrotechnica, vol. 11, no. 10, University of Ljubljana.

[4] Kim, J.K. (2004). Controls over bedrock channel incision. Ph.D. thesis, University of Glasgow, Glasgow.

[5] Kryžanowski, A., Mikoš, M., Šušteršič, J., Planinc, I. (2009). Abrasion Resistance of Concrete in Hydraulic Structures. American Concrete Institute (ACI) Material Journal, vol. 106, no. 4, p. 349-356.

[6] Horszczaruk, H. (2004). The model of abrasive wear of concrete in hydraulic structures. Wear, no. 256, p. 787796, DOI:10.1016/S0043-1648(03)00525-8.

[7] Horszczaruk, H. (2005). Abrasion resistance of highstrength concrete in hydraulic structures. Wear, no. 259, p. 62-69, DOI:10.1016/j.wear.2005.02.079.

[8] Horszczaruk, H. (2008). Mathematical model of abrasive wear of high performance concrete. Wear, no. 264, p. 113-118, DOI:10.1016/j.wear.2006.12.008.

[9] Horszczaruk, H. (2009). Hydro-abrasive erosion of high performance fiber-reinforced concrete. Wear, no. 267, p. 110-115, DOI:10.1016/j.wear.2008.11.010.

[10] Hu, X.G., Momber, A.W., Yin, Y., Wang, H., Cui, D.M. (2004). High-speed hydrodynamic wear of steel-fibre reinforced hydraulic concrete. Wear, no. 257, p. 441450, DOI:10.1016/j.wear.2004.01.019.

[11] DIN 52108. (2010). Wear test using the grinding wheel according to Böhme.

[12] ASTM C 779/C-779M. (2005). Standard test method for abrasion resistance of horizontal concrete surfaces.

[13] Jakobs, F., Winkler, K., Hunkeler, F., Volkart, P. (2001). Betonabrasion im Wasserbau, Miteilungen der Versuchsanstalt für Wasserbau, Hydrologie und
Glaziologie, no, 168. Eidgenössische Technische Hochschule (ETH), Zürich.

[14] Aquaro, D. (2010) Impact of solid particulate on brittle materials. Strojniški vestnik - Journal of Mechanical Engineering, vol. 56 no. 4, p. 275-283.

[15] Borkowski, P. (2010). a novel technique for spatial objects shaping with a high-pressure abrasive water jet. Strojniški vestnik - Journal of Mechanical Engineering, vol. 56 no. 5, p. 287-294.

[16] Šetina, B. (1969). Technical report: Determination abrasion resistance of various materials exposed to abrasion erosion. Hydraulic Laboratory, Ljubljana. (in Slovenian)

[17] Liu, T.C. (1981). Abrasion Resistance of Concrete. ACI Journal, vol. 78, no. 5, p. 341-350.

[18] ASTM C 1138M.-05 (2006). Standard Test Method for Abrasion Resistance of Concrete (Underwater Method). Annual Book of ASTM Standards, vol. 04.02, American Society for Testing and Materials, West Conshohocken, p. 621-624.

[19] Bania, A. (1989). Bestimmung des Abriebs und der Erosion von Betonen mittels eines GesteinsstoffWassergemisches, Ph.D. thesis, TH Wismar.

[20] Kryžanowski, A., Šušteršič, J. (2003). Performance of concrete exposed to long-term underwater abrasion loading, 21st Congress of International Commission on Large Dams ICOLD Montreal, Proceedings, Q.82-R.13, p. 207-218.

[21] Colarič, O. (1985). Technical report No. 831: Estimation of river bed and water level rise in the Vrhovo storage reservoir. Hydraulic Laboratory, Ljubljana. (in Slovenian)

[22] Šušteršič, J., Kryžanowski, A., Planinc, I., Zajc, A., Dobnikar, V., Leskovar, I., Ercegovič, R. (2004). Technical report: Performance of concrete exposed to underwater abrasion loading. Institute for research in materials and applications, Ljubljana. (in Slovenian):

[21] Mlačnik, J. (1999). Technical report No. 806: Measurement of turbidity and sediment transport in the Vrhovo storage reservoir. Institute for hydraulic research, Ljubljana. (in Slovenian)

[22] Mlačnik, J. (2004). Technical report No. 857: Hydraulic model research of Boštanj HPP. Institute for hydraulic research, Ljubljana. (in Slovenian) 